\title{
Using Spirometry to Appropriately Diagnose COPD
}

\author{
Tessa Robrberg, MD, Resident Representative, Editorial Advisory Board
}

Ann Fam Med 2015;13:iii. doi:10.1370/afm.1722.

$\mathrm{T}$ The Annals of Family Medicine encourages readers to develop a learning community of those seeking to improve health care and health through enhanced primary care. You can participate by conducting a RADICAL journal club and sharing the results of your discussions in the Annals online discussion for the featured articles. RADICAL is an acronym for Read, Ask, Discuss, Inquire, Collaborate, Act, and Learn. The word radical also indicates the need to engage diverse participants in thinking critically about important issues affecting primary care and then acting on those discussions. ${ }^{1}$

\section{HOW IT WORKS}

In each issue, the Annals selects an article or articles and provides discussion tips and questions. We encourage you to take a RADICAL approach to these materials and to post a summary of your conversation in our online discussion. (Open the article online and click on "TRACK Discussion: Submit a comment.") You can find discussion questions and more information online at: http://www.AnnFamMed.org/site/AJC/.

\section{CURRENT SELECTION}

\section{Article for Discussion}

van Dijk W, Tan W, Li P, et al. Clinical relevance of fixed ratio vs lower limit of normal of FEV1/FVC in COPD: patient-reported outcomes from the CanCOLD cohort. Ann Fam Med. 2015;13(1):41-48.

\section{Discussion Tips}

This article analyzes data from the cross-sectional phase of a population-based cohort study in Canada to examine the clinical relevance of different combinations of spirometry criteria for diagnosing chronic obstructive pulmonary disease (COPD). The study considers the impact of misdiagnosis of COPD while exploring diagnostic criteria and the relationship to clinically relevant disease.

\section{Discussion Questions}

- What question is asked by this study and why does it matter?

- How does this study advance beyond previous research and clinical practice on this topic?

- How strong is the study design for answering the question?

- What other modifying factors may be important to consider?

- To what degree can the findings be accounted for by:

1. How patients were selected, excluded, or lost to follow-up?

2. How the main variables were measured-both the diagnostic criteria and the outcome variables?

3. Confounding (false attribution of causality because 2 variables discovered to be associated actually are associated with a 3 rd factor)?

4. Chance?

5. How the findings were interpreted?

- What are the main study findings?

- How comparable is the study sample to similar patients in your practice? What is your judgment about the transportability of the findings?

- What contextual factors are important for interpreting the findings?

- How might this study change your practice? Policy? Education? Research?

- Who the constituencies are for the findings, and how they might be engaged in interpreting or using the findings?

-What are the next steps in interpreting or applying the findings?

- What might be the financial impact of this study's results?

- What researchable questions remain?

\section{References}

1. Stange KC, Miller WL, McLellan LA, et al. Annals Journal Club: It's time to get RADICAL. Ann Fam Med. 2006;4(3):196-197. http:// annfammed.org/content/4/3/196. 